\title{
Analisis Perbandingan Word Of Mouth Marketing dan Social Media Marketing dalam Menarik Minat Mahasiswa dalam Memilih Universitas (Studi Empiris pada Mahasiswa Universitas Pamulang)
}

\author{
Ajimat \\ Universitas Pamulang \\ math.unpam@gmail.com
}

\begin{abstract}
Penelitian dilakukan sebagai upaya mengetahui perbandingan antara metode pemasaran yang paling efektif dalam menarik minat mahasiswa bergabung dengan Universitas Pamulang. Pendekatan kuantitatif digunakan srebagai metode penelitian ini. Adapun jumlah sampel sebanyak 1557 responden yang tersebar ke dalam 50 kelas. Hasil penelitian menunjukan terdapat perbedaan antara metode word of mouth marketing dengan social media marketing dalam menarik minat mahasiswa bergabung dengan Universitas Pamulang. Metode word of mouth marketing 1,5 kali lebih efektif dibandingkan dengan social media marketing. Pada penggunaan metode word of mouth marketing, perantara yang paling dominan dalam mempengaruhi pilihan mahasiswa adalah teman, disusul oleh tetangga dan keluarga. Pada penggunaan media social, instagram, facebook dan website adalah tiga besar media sosial yang paling berperan dalam social media marketing. Pada pengujian statistik untuk menguji perbedaan antara kedua metode tersebut, terlihat bahwa ada perbedaan antara metode word of mouth marketing dengan metode social media marketing dalam menarik minat kuliah di Universitas Pamulang.
\end{abstract}

Keywords: pemasaran; word of mouth marketing; social media marketing.

Abstract. The research was conducted as an effort to find out the comparison between the most effective marketing methods in attracting students to join the University of Pamulang. The quantitative approach is used as a research method. The total sample of 1557 respondents spread into 50 classes. The results showed there were differences between word of mouth marketing methods and social media marketing in attracting students to join the University of Pamulang. The method of word of mouth marketing is 1.5 times more effective than social media marketing. In the use of word of mouth marketing methods, the most dominant intermediaries in influencing student choice are friends, followed by neighbors and family. In the use of social media, Instagram, Facebook and websites are the top three social media that play the most role in social media marketing. In statistical testing to test the differences between the two methods, it appears that there is a difference between the word of mouth marketing method and the social media marketing method in attracting interest in studying at Pamulang University.

Key words: Marketing; word of mouth marketing; social media marketing. 


\section{A. PENDAHULUAN}

Memilih sebuah universitas untuk menjadi sebuah tujuan dalam belajar di perguruan tinggi bukanlah hal yang mudah bagi calon mahasiswa yang ingin melanjutkan studi mereka. Dalam menentukan studi, mahasiswa banyak sekali memiliki pertimbangan untuk memilih sebuah perguruan tinggi. Melihat banyak variabel yang menjadi pertimbangan dalam menentukan sebuah pilihan perguruan tinggi, maka universitas pun memiliki banyak cara untuk menarik minat mereka untuk masuk dan memilih kampus mereka sebagai pilihan dalam menuntut ilmu. Penelitian ini mengerucutkan studi pada penggunaan metode pemasaran yang digunakan oleh salah satu universitas swasta yang memiliki jumlah mahasiswa sangat banyak dan lebih dari 80 ribu meskipun baru berdiri tahun 2001, Ajimat (2019). Penelitian ini mencoba untuk melihat perbandingan dua metode pemasaran yaitu word of mouth (WoM) marketing dan social media (SM) marketing yang coba ditelusuri kepada mahasiswa yang berada di Universitas Pamulang. Studi ini penting dilakukan sebagai sebuah strategi untuk melihat efektifitas dari kedua strategi tersebut dalam rangka meningkatkan dan menarik minat calon mahasiswa untuk memilih universitas Pamulang.

Beberapa penelitian terdahulu yang menggunakan variabel tersebut sebagai upaya untuk melihat keputusan pembelian sebuah produk, diantaranya L Moriansyah (2015), Nugraha, dkk (2015), Pratama (2017), Mahdiasukma dan Fauzi (2018), Mileva dan Fauzi DH (2018), dan Joesyiana (2018). Penelitian yang dilakukan sebelumnya hanya sebatas menggunakan satu variabel saja yaitu pengaruh word of mouth metode yang diteliti untuk melihat pengaruhnya terhadap variabel terikat yaitu keputusan pembelian atau pengaruh variabel social media marketing sebagai variabel bebas terhadap variabel terikat yaitu keputusan pembelian. Hasil penelitian terdahulu belum banyak yang mengungkap tentang perbandingan dan uji beda antara kedua metode tersebut terhadap keputusan pembelian sehingga peneliti tertarik untuk melakukan hal baru dengan menguji perbedaan kedua metode tersebut serta menguji perbedaan antara dua metode tersebut sehingga terpapar jelas perbandingan antara kedua metode yang digunakan.

Tujuan utama yang hendak dicapai dari penelitian ini adalah untuk melihat efektivitas kedua metode pemasaran sehingga pihak Universitas Pamulang dapat meningkatkan strategi marketing sebagai upaya untuk meningkatkan jumlah mahasiswa yang ada di Universitas Pamulang. Tidak hanya itu, penelitian ini juga dilakukan sebagai upaya untuk menguji hipotesis tentang ada atau tidaknya perbedaan antara kedua metode pemasaran tersebut. Urgensi dari penelitian ini sebagai upaya untuk melihat perbandingan kedua metode tersebut sehingga pihak Universitas Pamulang dapat menentukan langkah strategis untuk meningkatkan jumlah mahasiswa.

\section{B. KAJIAN LITERATUR}

Penelitian ini menggunakan beberapa variabel penelitian sehingga perlu penelusuran terhadap kajian literatur yang dapat membantu dalam memahami istilah-istilah yang relevan dengan penelitian tersebut.

Metode pemasaran dengan word of mouth menurut Kotler dan Garry (1998) merupakan sebuah bentuk komunikasi yang diberikan oleh seseorang kepada pihak tertentu terhadap pihak lain melalui mulut. Tujuannya adalah untuk mempengaruhi pihak lain agar mengikuti apa yang disampaikan oleh pihak tersebut. Adapun Rangkuti (2010) mengatakan bahwa komuniaksi dengan menggunakan WoM dilakukan secara sukarela untuk mempromosikan barang atau jasa kepada orang lain. 
Adapun metode pemasaran dengan media sosial menurut Gunelius (2011:10) social media marketing merupakan suatu bentuk pemasaran untuk memberikan promosi dengan menggunakan alat dari web sosial. Beberapa elemen yang digunakan dalam kesuksesan penggunaan media sosial dalam pemasaran yaitu content creation, content sharing, connecting, dan community building. Content creation berkaitan dengan isi dari media sosial tersebut dan harus dibuat secara menarik; content sharing berkaitan dengan pembagian konten kepada masyarakat lain; connecting berkaitan dengan jejaring sosial yang bisa digunakan sebagai media promosi; dan community building digunakan untuk membangun komunitas melalui internet.

Keputusan pembelian menurut Sumarwan (2014:377) merupakan sebuah keputusan konsumen jika keinginan konsumen untuk membeli suatu barang mengenai barang apa yang akan dibeli, apakah membeli atau tidak, kapan membeli, dimana membeli, bagaimana cara membayarnya, dan sebagainya.

\section{METODOLOGI PENELITIAN}

Metode penelitian kuantitatif digunakan sebagai metode penelitian untuk memaparkan perbandingan antara dua metode pemasaran yang paling efektif antara word of mouth marketing dan social media marketing. Penelitian ini juga berupaya untuk menguji perbedaan antara kedua metode tersebut dengan menggunakan alat bantu statistik berupa uji anova. Data pada penelitian ini didapatkan dari data primer berupa kuesioner yang diberikan kepada mahasiswa sebanyak 1557 kelas yang tersebar ke dalam 50 kelas. Adapun kuesioner diberikan dengan menggunakan random sampling.

Penelitian ini menggunakan dua variabel yaitu variabel word of mouth marketing dan social media marketing. Pada penggunaan variabel word of mouth marketing, terdapat beberapa variabel yang dijadikan sebagai sarana yaitu teman, keluarga, orang tak dikenal, dan tetangga. Adapun pada media sosial, yang dijadikan sebagai sarana adalah facebook, website, instagram, twitter, dll. Adapun teknik analisis data yang digunakan untuk menguji hipotesis adalah dengan menggunakan uji anova untuk menguji ada atau tidaknya perbedaan antara penggunaan metode word of mouth marketing dan social media marketing.

\section{HASIL DAN PEMBAHASAN}

Penelitian ini dilakukan untuk mengkaji dua metode pemasaran yang digunakan oleh Universitas Pamulang (UNPAM) sebagai upaya untuk menarik minat calon mahasiswa untuk memilih UNPAM sebagai kampus pilihan. Penelitian dengan menggunakan data kuesioner yang telah diolah dengan menggunakan alat bantu komputer ini memberikan hasil yang dapat dilihat pada gambar berikut: 
ISSN NO. (PRINT) 2598-0823, (ONLINE) 2598-2893

\section{Metode Marketing dalam menarik minat mahasiswa bergabung dengan Universitas Pamulang}

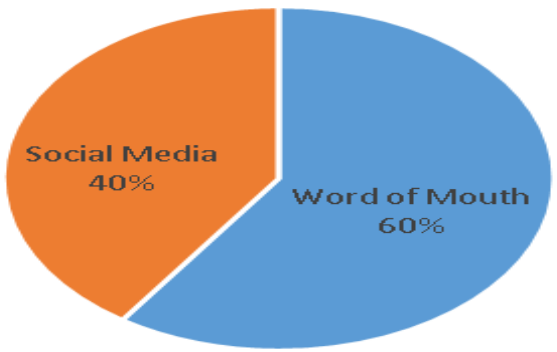

Gambar 1. Metode Marketing dalam menarik minat mahasiswa bergabung dengan Universitas Pamulang

Berdasarkan gambar 1 di atas, dapat dilihat bahwa metode marketing yang digunakan oleh Universitas Pamulang ada dua besar yaitu word of mouth dan media sosial. Hasil penelitian menunjukkan bahwa metode pemasaran word of mouth lebih efektif dan banyak digunakan oleh mahasiswa dalam upaya memilih kampus UNPAM sebagai pilihan untuk belajar. Berdasarkan olah data, terlihat bahwa $60 \%$ word of mouth digunakan oleh calon mahasiswa sedangkan media sosial sebanyak $40 \%$. Adapun sebaran perantara dalam menarik minat mahasiswa untuk bergabung dengan UNPAM dapat dilihat pada gambar 2 berikut:

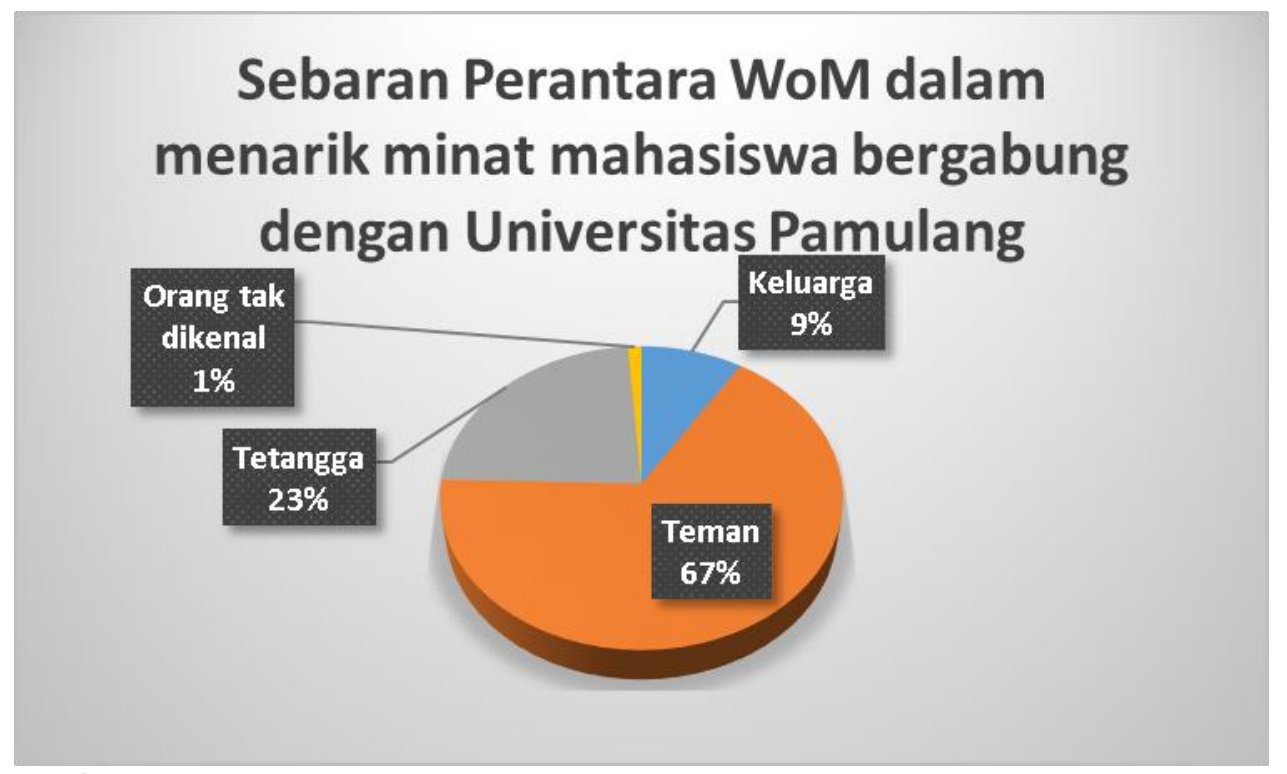

Gambar 2. Sebaran Perantara Word of Mouth Marketing dalam menarik minat mahasiswa bergabung dengan Universitas Pamulang 
Berdasarkan gambar 2 terlihat bahwa teman merupakan perantara yang banyak menarik perhatian dari calon mahasiswa baru yaitu sebanyak $67 \%$, yang diikuti oleh tetangga $23 \%$, keluarga $9 \%$, dan orang tak dikenal $1 \%$. Melihat bahwa teman merupakan perantara yang paling dominan dalam menentukan pilihan mahasiswa, oleh karena itu, Universitas Pamulang dapat melakukan promosi melalui mahasiswa yang sudah belajar di UNPAM dengan memberikan pelayanan yang maksimal sehingga mahasiswa yang belajar di UNPAM merasa nyaman dan pada akhirnya akan menyebarkan informasi bahwa mereka mendapatkan pelayanan dan pendidikan yang maksimal di UNPAM.

Adapun pada penggunaan media sosial, sebaran penggunaan media sosial dalam menarik minat mahasiswa dapat dilihat pada gambar 3 berikut:

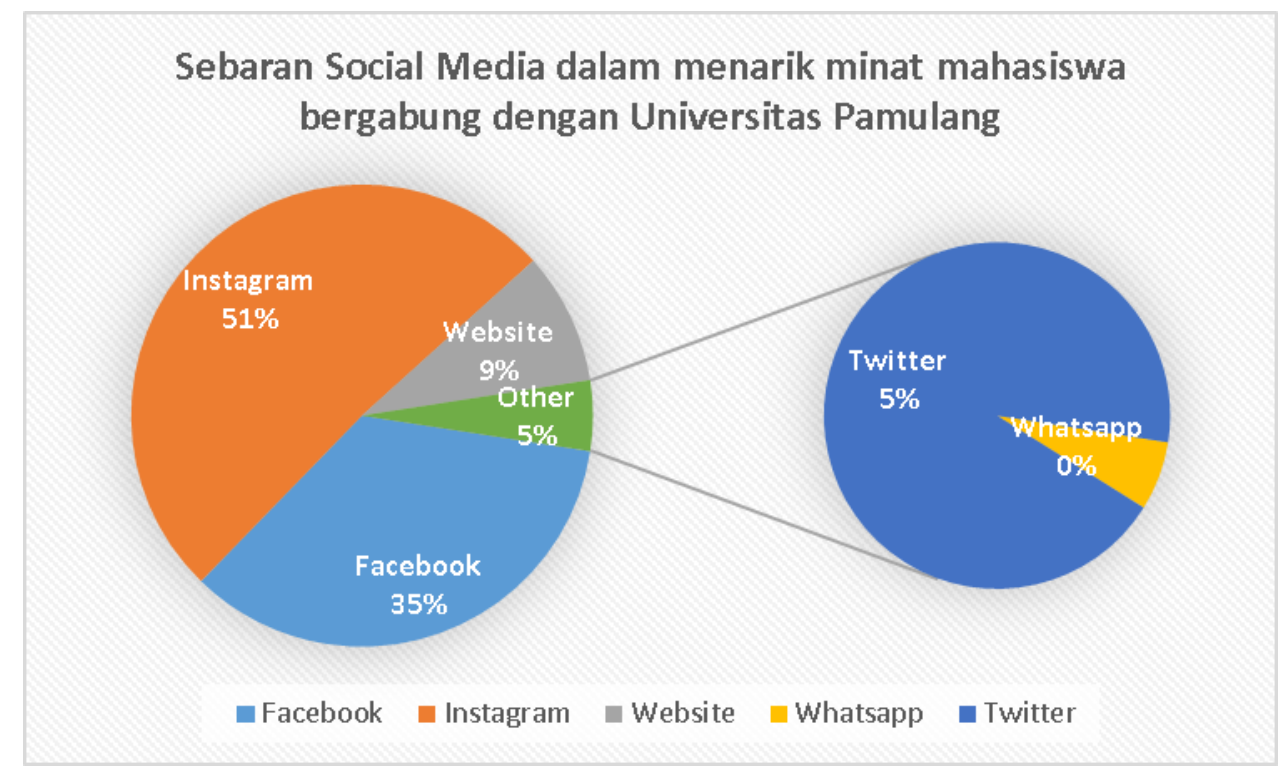

Gambar 3. Sebaran Media Sosial dalam menarik minat mahasiswa bergabung dengan Universitas Pamulang

Berdasarkan gambar 3, dapat dilihat bahwa sebaran penggunaan media sosial yang digunakan oleh UNPAM dalam mempromosikan UNPAM yaitu instagram, website, twitter, facebook dan whatapps. Berdasarkan hasil olah data, dapat dilihat bahwa media sosial yang paling dominan berperan dalam menarik mahasiswa yaitu instagram sebanyak $51 \%$, facebook sebanyak $35 \%$, website $9 \%$, twitter dan yang lainnya $5 \%$. Mengingat bahwa instagram adalah media paling dominan, maka pihak universitas dapat meningkatkan media sosial tersebut untuk meningkatkan minat calon mahasiswa dalam menentukan pilihan universitas.

Penelitian ini juga dilakukan sebagai upaya untuk menguji perbedaan antara kedua metode pemasaran tersebut. Oleh karena itu, perlu dilakukan beberapa pengujian untuk menguji hipotesis yang diajukan dalam penelitian ini untuk melihat ada atau tidaknya perbedaan antara metode word of mouth dan social media marketing dalam upaya pemilihan minat mahasiswa dalam menentukan pilihan universitas. Adapun syarat dalam menguji hipotesis data harus berdistribusi normal dan data harus berasal dari varian yang sama. 
ISSN NO. (PRINT) 2598-0823, (ONLINE) 2598-2893

Tabel 3

Hasil Uji Normalitas

Tests of Normality

\begin{tabular}{|c|r|r|r|r|r|r|}
\hline \multirow{2}{*}{} & \multicolumn{3}{|c|}{ Kolmogorov-Smirnova } & \multicolumn{3}{c|}{ Shapiro-Wilk } \\
\cline { 2 - 7 } & Statistic & df & Sig. & Statistic & \multicolumn{1}{c|}{ df } & \multicolumn{1}{c|}{ Sig. } \\
\hline WoM &, 184 & 50 &, 000 &, 919 & 50 &, 002 \\
\hline
\end{tabular}

a. Lilliefors Significance Correction

Hasil pengujian menggunakan metode Kolmogorov-Smirnov maupun Shapiro-Wilk menunjukkan bahwa nilai Sig. lebih kecil dari 0,05, yang berarti data berdistribusi normal.

Tabel 3

Hasil Uji homogenitas

\begin{tabular}{|c|c|c|c|}
\hline \multicolumn{4}{|c|}{ Test of Homogeneity of Variances } \\
\hline \multicolumn{4}{|l|}{ Nilai } \\
\hline Levene Statistic & df1 & df2 & Sig. \\
\hline 3,961 & 1 & 98 & ,069 \\
\hline
\end{tabular}

Hasil uji homogenitas menunjukkan bahwa nilai Sig. lebih besar dari 0,05 yang berarti varian kedua kelompok tersebut adalah sama.

Berdasarkan dua syarat tersebut, maka dapat dilanjutkan ke pengujian hipotesis untuk menguji hipotesis berikut ini:

Ho : Tidak ada perbedaan antara metode WOM dengan metode SMM dalam menarik minat kuliah di Universitas Pamulang

$\mathrm{Ha}$ : Ada perbedaan antara metode WOM dengan metode SMM dalam menarik minat kuliah di Universitas Pamulang

Untuk menguji hipotesis tersebut, maka digunakan uji Anova. Hasil pengujian sesuai dengan tabel berikut:

Tabel 3

Hasil Uji Anova

\begin{tabular}{|l|r|r|r|r|r|}
\hline \multicolumn{7}{|c|}{ ANOVA } \\
\hline Nilai & $\begin{array}{l}\text { Sum of } \\
\text { Squares }\end{array}$ & df & $\begin{array}{c}\text { Mean } \\
\text { Square }\end{array}$ & F & Sig. \\
\hline $\begin{array}{l}\text { Between } \\
\text { Groups }\end{array}$ & 894,010 & 1 & 894,010 & 35,292 &, 000 \\
\hline
\end{tabular}

Jurnal Pemasaran Kompetitif, Vol. 3, No. 2 / Februari 2020 
ISSN NO. (PRINT) 2598-0823, (ONLINE) 2598-2893

\begin{tabular}{|l|r|r|r|r|l|}
\hline Within Groups & 2482,500 & 98 & 25,332 & & \\
\hline Total & 3376,510 & 99 & & & \\
\hline
\end{tabular}

Berdasarkan tabel anova di atas, terlihat bahwa nilai Sig. lebih kecil dari 0,05. Berdasarkan hasil tersebut maka Ho ditolak dan Ha diterima. Hal ini berarti ada perbedaan antara metode WOM dengan metode SM dalam menarik minat kuliah di Universitas Pamulang. Artinya bahwa pihak UNPAM dapat menggunakan kedua metode tersebut secara bersamasama dengan mempertimbangkan efektifitas dari kedua metode tersebut.

\section{E. KESIMPULAN}

Hasil penelitian ini menyimpulkan bahwa penggunaan metode word of mouth 1,5 kali lebih efektif dibandingkan dengan social media marketing. Adapun variabel yang paling dominan sebagai perantara untuk menarik minat mahasiswa adalah teman. Hal ini berarti bahwa teman merupakan variabel yang sangat penting dalam menentukan minat mahasiswa dalam memutuskan untuk memilih sebuah perguruan tinggi. Oleh karena itu, pihak Universitas Pamulang harus bisa memberikan pelayanan yang terbaik kepada mahasiswa sehingga apa yang mereka dapatkan selama belajar di perguruan tinggi dapat disebarluaskan kepada teman-temannya yang ingin memilih perguruan tinggi. Hal ini sangat penting mengingat bahwa metode pemasaran ini jauh lebih efektif dibandingkan dengan menggunakan media sosial. Tidak hanya itu, tidak dapat dipungkiri juga bahwa media sosial juga sangat berperan penting dalam menarik minat mahasiswa untuk menentukan universitas yang ia pilih. Berdasarkan hasil penelitian ini, diperoleh data bahwa media sosial yang paling dominan dalam membantu mahasiswa untuk menentukan pilihan universitas yaitu instagram, facebook dan website. Menyikapi hal tersebut, pihak Universitas Pamulang dapat memanfaatkan media sosial tersebut sebagai upaya untuk melakukan promosi kepada calon mahasiswa baru.

\section{DAFTAR PUSTAKA}

Ajimat, A. (2019). PERAN KOMITMEN ORGANISASI DALAM PENGARUH NEGATIF TURNOVER INTENTION TERHADAP LOYALITAS KARYAWAN (Studi Kasus di Universitas Pamulang). Jurnal Ekonomi Efektif, 2(1).

Ilham Adji Putra Pratama, I. (2017). Komunikasi Word of Mouth dan Keputusan Pembelian Produk Batik Bangkalan. Komunikasi Word of Mouth dan Keputusan Pembelian Produk Batik Bangkalan, 3(2), 285-295.

Joesyiana, K. (2018). THE EFFECT OF WORD OF MOUTH ON CONSUMER PURCHASING DECISIONS AT SHOPEE (ONLINE SHOP) IN PEKANBARU. VALUTA, 4(1), 71-85.

Kotler, P dan Garry A. (1998). Dasar-Dasar Pemasaran. Jakarta: Prenhallinda

Mahdiasukma, P., \& Fauzi, A. (2018). Pengaruh Word of Mouth Marketing terhadap Keputusan Pembelian (Survei pada Konsumen Coffee Toffee cabang Kota Malang). Jurnal Administrasi Bisnis, 55(3), 55-63.

Mileva, L., \& Fauzi DH, A. (2018). Pengaruh Social Media Marketing Terhadap Keputusan Pembelian (Survei Online pada Mahasiswa Sarjana Jurusan IImu Administrasi Bisnis Angkatan 2014/2015 Fakultas IImu Administrasi Universitas Brawijaya yang Membeli Starbucks Menggunakan LINE). Jurnal Administrasi Bisnis, 58(1), 181-189.

Moriansyah, L. (2015). PEMASARAN MELALUI MEDIA SOSIAL: ANTECEDENTS DAN CONSEQUENCES SOCIAL MEDIA MARKETING: ANTECEDENTS AND 
CONSEQUENC-ES. Jurnal Penelitian Komunikasi dan Opini Publik Vol, 19(3), 187196.

Rangkuti, F. (2010). Spriritual Leadership in Business, Jakarta: PT. Gramedia Pustaka Utama 